\title{
Evolution of Institutional Logics: The Emergence of the Temporary Work Agencies Field in Italy
}

\author{
Alessia Berni ${ }^{1}$, Mariavittoria Cicellin ${ }^{2}$, Stefano Consiglio ${ }^{3} \&$ Luigi Moschera ${ }^{1}$ \\ ${ }^{1}$ Department of Business and Economics, University of Naples "Parthenope", Naples, Italy \\ ${ }^{2}$ Department of Economics, Management and Institutions, University of Naples Federico II, Naples, Italy \\ ${ }^{3}$ Department of Social Sciences, University of Naples Federico II, Naples, Italy \\ Correspondence: Mariavittoria Cicellin, Department of Economics, Management and Institutions, University of \\ Naples Federico II, Naples, NA, Italy. E-mail: mariavittoria.cicellin@unina.it
}

Received: June 22, 2017

doi:10.5539/ijbm.v12n8p131
Accepted: July 14, 2017

Online Published: July 18, 2017

\begin{abstract}
This article shows the process of creation and evolution of an organizational field. By an in-depth longitudinal analysis, we investigate the field of Temporary Work Agencies in Italy (TWAs). The article focuses on how a field evolves over time. We delineate three phases of evolution - incubation, emergence and development - and we analyse events and the role of actors that have characterized them. Further, we identify the institutional logics that have strongly influenced the strategic and organizational behaviour of the actors involved in the Italian field of TWAs and their interactions. Therefore, to respond to this institutional complexity the actors have tried to influence with both individual and collective actions the logics themselves. The analysis shows that two competing logics have coexisted within the TWA field: the regulation logic, inspired by the social status and welfare, and the de-regulation logic, connected to the liberal and free-market model. Through the longitudinal analysis repeated in four different field studies, we have reconstructed the process of evolution of the field, describing the links between the different phases. Our research contributes to the institutional logic perspective fitting into the discussion on the coexistence of competing logics in an organizational field.
\end{abstract}

Keywords: Institutional logics, longitudinal analysis, organizational field, temporary work agencies

\section{Introduction}

The evolution of organizational fields can be analysed through the new institutional approach. Not only does the behaviour of the actors influence organizational fields but also many occurring events shape and modify the institutional frame and trigger for organizational change. The evolution of an organizational field can be analyzed as a process of interplay between actors and actions in which institutional events are both random and direct manifestations of actions (e.g. Thornton \& Ocasio, 2008; Greenwood, Oliver, Suddaby, \& Sahlin, 2008; Thornton, Ocasio, \& Lounsbury, 2011).

Through an in-depth longitudinal analysis (from 1986 to 2009), we investigate how a field evolves over time, describing the emergence and the evolution of the Italian temporary work agencies field (TWAs). In particular, through the analysis of events, logics and actors' roles which animate the field we can identify three phases of evolution: incubation, emergence and development phase.

The aim is twofold: to identify the institutional logics that have influenced the TWAs field in the different stages of development, which are particularly significant for the understanding of the peculiar field and the Italian labour market; to analyse the role of individual and collective actors through the study of the events that shape both the actions and the institutional logics. Further, we highlight how the process of emergence and evolution results in the actions of collective and individual actors, reflecting the competition between dominant and emerging logic.

The research shows that two competing logics have coexisted within the field of TWAs. In our research context the regulatory frame has strongly influenced the strategic and organizational behaviour of the actors involved in the Italian field of TWAs and their interactions. There is a multiple embeddedness between logics of a higher level that shape lower level logics and, at the same time, are conditioned by them. The actors influence institutional logics through a mutual conditioning. Moreover, to respond to this institutional complexity the 
actors have tried to influence with both individual and collective actions the logics themselves. In this sense, it is worth to underline the organizational complexity of the TWAs field and its influence on organizational behaviour and practices (Greenwood, Rayanard, Kodeih, Micelotta, \& Lounsbury, 2011). As a matter of fact, we study the relationship between events and logics: critical events occurred in the field of TWAs caused the shift from one phase to another and from one institutional logic to another at field level, leading to a change of behaviour of field's actors. From this point of view, we highlight how players in a field interpret and respond to the events.

Our research contributes to new institutional studies on the institutional logic perspective fitting into the discussion on the coexistence of competing logics in an organizational field.

The rest of the article is structured as follows. We will first provide a theoretical background focusing on the literature about institutional logics. Then, we describe our methodology and the different phases that have characterized the emergence and the evolution of the field. Finally, we describe our findings in order to highlight the events occurring during the period studied and the coexistence of competing logics in the field. Finally, we formulate some final considerations and address future steps of the research.

\section{Theoretical Background: Institutional Logics in the Organizational Perspective}

The institutional logic approach in organizational studies is useful for understanding the behaviour of individuals and organizations within a wider system of values and beliefs (Thornton \& Ocasio, 1999; Lounsbury, 2007). Institutional logics provide the rules of the game (Durand \& Jorudan, 2012). They are the fundamental principles of society able to drive social action and represent patterns that provide actors principles, values and assumptions, which are often embedded, to understand organizational realities (Thornton, 2004). According to this perspective, organizational forms, managerial practices and behaviour are manifestations of institutional logics and are justified by the same.

According to Friedland and Alford (1991), the logics are fundamental theoretical constructs that can explain the relationship between actors of an organizational field. Moreover, logics can be considered a way to determine the impact that institutions have on the behaviour of individuals and organizations by guiding actions and practices (Friedland \& Alford, 1991; Thornton, 2004; Thornton \& Ocasio, 2008).

The interests, values and assumptions of individuals and organizations are embedded within the existing institutional logics. It can be said that there is mutual conditioning: on the one hand, the institutional logic influences the behaviour of the actors and, on the other hand, the institutional logics is influenced by the actors, both individual and collective (Seo \& Creed, 2002; Greenwood \& Suddaby, 2006). Furthermore, organizational fields have specific logics that are embedded in one or more broader institutional or social orders such as the market, state, family, religion, companies, professions, etc. (Thornton, 2004). Every social system is characterized by a peculiar logic related to material and managerial practices (Friedland \& Alford, 1991; Reay et al., 2009), and significant institutions have a central logic that guides and binds individual and collective behaviours. The current debate on institutional logics considers the institutional process as a result of coexistence and interaction of multiple logics. According to this perspective, the organizations and, more generally the society, are governed by a plurality of coexisting logics. Many institutional theorists have argued that organizational fields are organized according to a dominant institutional logic, even though some studies recognize that two or more institutional logics may exist at the same time (Thornton \& Ocasio, 1999; Scott, 2008; Greenwood et al., 2008).

In literature we can find different ways of conceptualizing the relationship between multiple logics (Reay et al., 2009, Westenholz, 2011; Nicolini et al., 2016). Some authors argue that among logics there is a dominant one which guides behaviours and in this conceptualization, different institutional logics coexist within an organizational field, challenging each other to become dominant and pushing for radical or incremental changes. Logics are presented as being in competition, and secondary logics are considered drivers of change as they are used to explain shifts from one logic to another (Thornton \& Ocasio, 1999; Scott et al., 2000; Thornton, 2002; Lounsbury, 2002). Moreover, other scholars show the presence of long periods of struggle among logics, where competing multiple logics co-exist for lengthy transition periods (Hensman, 2003; Hoffman, 1999). Finally, some studies suggest that multiple logics co-exist influencing different actors and organizations (Lounsbury, 2007, Marquis \& Lounsbury, 2007; Reay et al., 2009; Reay \& Hinings, 2009). Although some scholars analyze and describe the coexistence and competition of several institutional logics underlying field level changes (Lounsbury \& Crumley, 2007; Reay \& Hinings, 2009), others analyze the way the organizations adapt to alternative or minority logics (Greenwood et al., 2010; Durand \& Jorudan, 2012).

From this stream of the literature emerges that in many fields leading players establish a prevailing institutional logic while the other actors who have different ideas and practices try to diverge from the dominant logic. The holders of a so called "minority" logic promote a way to contrast the dominant logic which prevails in the field 
(Durand \& Jorudan, 2012).

\section{Methodology and Data Collection}

Our longitudinal analysis employs both archival and primary data.

Archival data cover a span of almost 25 years from 1986 to 2009, including government documents, materials available through specialized press and trough agencies, financial statements as well as financial reports and planning documents of the TWAs surveyed.

Our primary data consist of four field observations $(2000 ; 2005 ; 2007 ; 2009)$ and 147 interviews that were conducted during the years (see Appendix A for complete proofs and information on data and field studies). We interviewed key actors, managers and CEOs of TWAs, institutional union managers, chiefs of trade associations and experts in the field.

We sequenced our study as follows:

a) in-depth study of archival material to understand the phenomenon and to reconstruct events and dynamics of the period from 1986 to 1999. In this study we run 20 semi-structured interviews to trade unionists, actors involved in lobbying, trade association executives, managers and CEOs of TWAs to know their opinions. Results from interviews have helped us to better understand role of actors involved in the emergence of the new field;

b) first detailed field study (2000): the survey has involved 30 TWAs and we run 40 semi-structured interviews;

c) second field study (2005): the survey has involved 40 TWAs and we run 33 semi-structured interviews;

d) third field study (2007): the survey has involved 31 TWAs and we run 32 semi-structured interviews;

e) fourth field study (2009): the survey has involved 36 TWAs and we run 22 semi-structured interviews.

A further methodological clarification should be made regarding the classification of the events analysed in the next section of this work. In particular, we identified a list of events that, to differing degrees, affected the institutional life of the field and the TWAs in the three main phases. We submitted to our interviewees this list, asking them to express an opinion on the importance of each event, using a graduated response scale. Finally, we have grouped events according to the strength dimension (weak/strong) and to the origin dimension (exogenous/related to the field).

\section{The Evolution of the Italian Temporary Work Agencies Field}

Although many European countries and USA made use of temporary employment opening the doors to new type of contracts already in 60 's, Italy was hindering its introduction into the employment framework and in the labour market mainly due the lack of interest and to the existence of various constraints and contextual factors.

The Italian historical context imposed a rigid regulation of the labour market that provided for the recruitment of workers exclusively through standard full time permanent employment contract. This led to a "demonization" attitude towards the temporary work contract, actually called agency work, and all forms of "atypical" work. Agency work supporters use the word "demonization" (as results from the interviews) to describe the hostile attitude of several actors (trade unions, leftist parties and extra-parliamentary left-wing formations, social centres, etc.) who, in those years (but also afterwards), tried to halt the introduction of the contract in Italy. Therefore, in this situation, the emergence and evolution of the new TWAs organizational field was long and complex. We have divided into three main phases, according to the main events occurred in those years:

- The incubation phase (1986-1997).

- The emergence phase (1997-2003).

- The development phase (2003-2009).

The incubation phase (1986-1997)

In the incubation phase fierce debates gave rise to cultural and ideological clashes. During this period, information activities, strong lobbying, intense negotiations and legal actions took place to spread the knowledge about temporary agency contract, but also wanted to determine the structural and regulatory features needed for the future organizational field.

In 1986, the Labour Minister at the time, involved in the Socialist Party, presented a law that triggered the incubation period. This was the first serious attempt to start a debate on the introduction of the temporary agency employment contract in Italy. 
A multinational work agency entered the Italian labour market after the presentation of the Law. In 1989, ADIA, a Swiss multinational and world leader in the industry, gained control of Syntex, a Milan-based company focused on HR recruitment, with the purpose of promoting a policy aimed at accelerating the introduction of the new type of contract in an attractive market such as the Italian one. This event and the Italian management of Syntex led to the lobbying to raise awareness and to start the endorsement of temporary agency employment in Italy.

Non-institutional actors - including Italian human resource management consulting companies interested in broadening their range of action - put in place lobbying activities to encourage the implementation of temporary agency employment. As a consequence, the entry of these actors in this scenario gave a boost to the legitimation process. These companies started to disseminate information about the main feature of the contract and the related benefits through trade press articles and seminars and workshops addressed to trade unions, opinion leaders, labour policy makers of leading political parties and representatives of associations.

At the same time, some actors played an equally significant role within political institutions and trade unions since they supported the introduction of temporary agency employment more than others. In this way, they became key players with a networking role between actors arguing in favour and against the type of contract.

At the beginning of the 1990s three main events occurred:

1. The European Union Directive no. 383 dated June 25th 1991 that urged national governments to reshape regulations in order to increase the employment levels by leveraging a more flexible labour market;

2. Legal Decree No. 1 dated January 5th 1993, which is also known as the "Mazzocca" Legal Decree, aimed at introducing the instrument, but never approved by Parliament nor reiterated by the Government;

3. The social pact dated July 23th 1993 that was signed by the Government, unions and business associations, which provided for the introduction of temporary agency employment in Italy. For the first time the Italian unions agreed to the establishment of the new type of contract.

In particular, the last event can be considered a strong one. The social pact is a momentous milestone in the institutionalization process because it changed the terms of the debate and shifted the focus from ideological problems to issues related to the definition of the main features of the upcoming new contract.

In this framework, foreign multinational TWAs continued to have a crucial role in the change process for the promotion and implementation of temporary agency employment. The "Club di Milano", which is an organization made up of the most prestigious multinational companies (Adia, Ecco, Vedior, Manpower and Randstad), was founded at the end of 1993. Moreover, in 1996, the lobbying activity was reinforced and the "Assilt" association was formed. Assilt involved some multinational corporations and many small Italian HR consulting companies that started to view temporary agency employment as a real market opportunity. At this stage of the field incubation process, a key question raised concerning the debate on the status of agency workers. On the one hand, trade unions argued that the worker had to be employed by the agencies on a permanent basis with an availability indemnity for periods of inactivity, and, on the other hand, TWAs saw this as an obstacle to the development of the field.

Towards the end of 1996, there was another battleground concerning the identification of the requirements and obligations that TWAs should have followed. On this issue, trade unions strongly pushed towards the introduction of strict requirements for the access to the temporary labour market, such as the obligatory presence in more than one Italian Region with multiple branches, the availability of a fixed share capital, the need to have significant security deposits and the exclusivity of the corporate purpose. This would have guaranteed access to mid-sized and large companies and prevented non-professional operators to access the field.

In 1997, after a long process, the so-called Treu Law (Law 196/1997 and related legislative and Ministerial provisions) was approved. This law formalized the temporary agency employment institution in Italy and legalized the activities of TWAs (defined as a temporary work agency), by defining the structural characteristics and limiting their scope to the management of agency employment and agency workers. The TWAs field is characterized by clear and well-defined boundaries, which are the result of the regulations that introduced temporary agency employment (Law 196/1997).

\section{The emergence phase (1997 - 2003)}

The Treu Law (Note 1) outlined a regulatory framework that characterized the field of companies providing temporary employment in Italy.

Temporary agency employment is a type of contract that regulates the relationship between three actors: the temporary work agency, the employee (the agency worker) and the user company, which may be a private or 
public organization. Thus, as known, temporary employment is characterized by a triangular relationship, through which a TWA assumes a worker with agency contract on a fixed-term basis (and in last years on a permanent basis too, according to the Italian legislation) and places him/her within the user company, that is the agency's client.

The Treu Law conditioned the emergence of the field by imposing a set of constraints on the agencies that formally defined the legitimizing template within the field.

As of today, we refer to the prohibition of replacing workers on strike, and workers in companies who have fired workers in the last two months, with agency workers. Moreover, agency contracts were forbidden for companies in downsizing and for replacing workers requiring special medical surveillance.

In January 1998, the first 11 agencies were authorized and started to provide temporary agency employment. At the end of 2003, 65 agencies were working nationwide. The field rapidly grew. Between 1997 and 2002, the turnover of the agencies grew from 128 thousand Euros to just over 3 million Euros, branches increased from 400 to more than 2000 and employees went from 1,360 to almost 7,000.

In this phase, the Treu Law also established two bilateral organizations: Ebitemp that bring together trade unions and trade associations and Forma.temp the bilateral association managing the funds for the temporary workers training. These associations carry out a wide range of activities: on the one hand, they manage funds and services (primarily training) and, on the other hand, provide the various parties involved (TWAs and unions) a discussion forum where they could share ideas and build collaborative relationships, on the behalf of agency workers.

In 2000, the existing TWAs grouped together into three different associations (Confinterim, AILT, APLA), playing a crucial institutional role, not just in carrying out lobbying strategies, but especially in providing information to reinforce the social legitimacy of agency work.

It is worth to emphasize the role of trade and enterprises associations: from 2000 onwards, they became involved in reinforcing the social acceptance of agency work.

Several events have characterized the emergence phase, influencing and changing the field of TWAs.

The Labour Minister at that time formed a committee to write the White Paper on the Italian labour market, the labour flexibility issue and the new forms of employment contracts (October 2001). This was a significant contribution to promote a more flexible labour market and, consequently, pushing towards the deregulation of employment. After this the government also began to challenge the so-called "article 18" of the Workers' Charter (Law 300/1970) falling under the "freedom of unions' association" and dealing with unjustified dismissals for certain categories of workers.

In 2002 within a climate of dissent, the Red Brigades (a Marxist - Leninist terrorist organization) killed the Professor Marco Biagi who joined the White Paper. Subsequently, in July 2002, the Government and the unions signed a national agreement regarding reforms and flexibility, but CGIL did not sign the agreement. Nonetheless, we must emphasize that this event has marked a split within trade unions and the consequent weakening of a highly regulated system.

In this context of reforms, the right-centre Government's strategy (led by Silvio Berlusconi) came to the definition of the Law 30/2003 and the implementation of Legal Decree No. 276 dated September 10th 2003, that deeply changed the regulatory framework of the field.

The development phase (2003-2009)

Law 30 of 2003, which is better known as the Biagi Law (together with Legislative Decree 276/2003) (Note 2), represents the event that launched the field's development phase, by introducing different changes that significantly affected its evolution. The Biagi Law substituted the Treu Law and integrated new elements, such as:

1. The legal cancellation of the brokerage and intervention ban (pursuant to law 1369/1960);

2. the repeal of the obligation to have a single business purpose: this enabled all employment agencies to enter the labour market by diversifying their range of services which not only included employment services but also a series of additional, related services (training, outplacement, staff leasing, job placement, etc.).

In 2003, with the Legislative Decree No. 276, a bilateral body, Ebiref, emerged for the additional wages and education for the leased workers hired with permanent contracts by the agencies.

Despite the drive towards liberalization, the Biagi Law retained some constraints, such as the prohibition of employment to replace workers that are on strike, the rules regarding the renewal and extension of the missions, 
and ensuring the protection of the employee's rights as provided for by the Workers' Statute.

Moreover, the law also established the setting up of a sole register of all the legally recognized and operating TWAs with the Ministry of Labour as well as, at the same time, introducing a single authorization system for TWAs.

In this scenario, it is useful to provide some details regarding the expansion of the field at that stage. During the development period, the TWAs industry increased significantly up to 2006 and then started to decline in 2008 .

In May 2006, the centre-left coalition won the elections with its program that included, as a key issue, the aim of reducing job insecurity.

The trend towards neo liberalism and greater deregulation of the labour market decreased with this new government. The short-lived government $(2006-2008)$ therefore almost failed to have an incisive effect on legislation and the election of the fourth Berlusconi government, with the Labour Ministry headed by Maurizio Sacconi (co-author of the "White Paper" aforementioned), marked a renewed phase of more extensive deregulation of the Italian labour market.

During these years, the global financial and economic crisis heavily affected the last developments in the field. There was a fall in demand due to a shock in the industry, since only extremely few agencies had predicted such a strong crisis. The optimistic expectations and forecasts of 2006/2007 that resulted from interviews with agency managers or from reading the reports to shareholders in the financial statements of 2008 were entirely disregarded.

Until September 2008 (the moment we identify with the beginning of the Italian socio-economic crisis), TWAs operated in a sector that had witnessed constant growth from the outset (with growth rates that often reached 10\%). In 2008-2009 figures show the dramatic restructuring and reduction of the TWAs industry: in particular, turnover backed to the levels of the previous four years, completely erasing the extraordinary development of the three-years period 2006-2008.

In order to fight the crisis that struck the global economy, On 23 December 2009, as part of the 2010 Budget (Law no. 191 "Disposizioni per la formazione del bilancio annuale e pluriennale dello Stato" [measures for the formation of annual and long-term budget]) the Italian parliament passed a series of measures designed to tackle the crisis that ravaged the world economy and reinforced the role of Italian TWAs. In particular, they included several innovations in the existing legislation that encouraged TWAs and reinforced their position within the labour market, extending their sphere of action in three significant directions:

1. Entrusting TWAs with an important role in active employment policies by assigning them the functions of outplacement for workers enrolled in unemployment lists;

2. removing a series of conditions in favour of fixed-term contracts (for those workers direct-hired by client organizations), making this type of contract equal to agency work, by equalizing the causes of the ban;

3. reinforcing the multifunctional role of TWAs by re-introducing staff leasing (introduced and then removed several times in previous legislative proceedings).

\section{Discussion}

\subsection{Evolution of TWAs Field: The Main Events}

The process of evolution of TWAs field is due to several events that caused many changes in the field. In particular, these transformations seem to be caused by different types of events.

We have distinguished between weak and strong events. This distinction depends on how much the event is able to erode the dominant logic, to resist to a competitive logic or activate an institutional change. We have identified the momentous events into strong and weak groups based on their ability to affect the dominant logic, to object the competing secondary logic and/or to activate institutional change.

A strong event can be a "breaking point" marking the transition from one logic to another or causing a significant institutional change, both in the presence of a coexistence of logic and the presence of a dominant logic (critical events, according to Reay et al., 2009). However, we highlight that weak events represent key moments in the evolution of an organizational field too.

Furthermore, we have classified the events based on their origin. These classifications included events that were directly related to the field specific institutional logic (field specific) and external events related to the basic logic, or the higher-level institutional order. 
The research carried out on the field of TWAs has highlighted the importance of events to understand the development process of the organizational fields and interdependence between logics and action (Meyer, Brooks, \& Goes,1990; Greenwood, Suddaby, \& Hinings, 2002; Nicolini et al., 2016). The analysis shows the existence of a series of inconsequential events that, nevertheless, represent significant moments in the evolution of the field under investigation and confirm the existence of an institutional logic in a certain period.

As already mentioned in the methodology section, we have classified the events during the three phases analysed, according to their importance and weight (strong/weak) and origin (exogenous or background events/events directly related to the field).

The De Michelis Law is the first strong event that breaks the balance by opening the debate on the possibility of temporary work in Italy, until then regarded a taboo topic. The fact that De Michelis was not an ordinary member of Parliament, but the Labour Minister, emphasizes the strength of this event.

The Mazzocca Law represents another point of attention in the lobbying activities taking place in Italy, but it received little attention by media and political debates, and also managers and other actors we have interviewed gave little evidence to this.

Amongst the strong events in the first phase, we highlight the creation of the "Club di Milano": an association made up of six leading multinational companies in the field with the purpose of coordinating the institutional lobbying activities and promoting temporary employment in Italy. These multinationals also acted independently, in this sense, we should take into consideration the Aida's (now Adecco) takeover of an Italian recruitment company (Syntex).

In the incubation phase, the strong event is the Treu Law dated 1997 that represents the formal emergence of the organizational field and is the result of all actions carried out in the period observed.

During the emergence phase of the field, the foundation of the bilateral organizations (Forma.temp and Ebitemp) can be considered the main strong event directly related to the field. In fact, Forma.temp and Ebitemp are essential meeting, mediation and negotiation points between the actors of the field.

In the emergence phase, numerous minor exogenous events provide a sense of existing social conflict that strongly marks the conflict between the two institutional logics: in particular, there is a battle preserving the "article 18" of the Workers' Statute and the murder of the Professor Marco Biagi.

Among the strong events external to the field, we should also remember the publishing of the White Paper on employment and the approval of legislative decree 276/2003 that significantly change the field by removing a set of constraints on TWAs activity, such as the corporate purpose and transforming the agencies into "multifunctional" operators, operating in different HR area.

During the development phase, there were a series of strong events directly connected to the organizational field. In particular, it is worth mentioning the introduction of welfare measures that Ebitemp directly introduced to support leased workers. These were aimed at strengthening the legitimation of agencies and creating conditions needed to change the 2010 Financial Law. Another significant event is the creation of Assolavoro, which united the TWAs into one association (involving Ailt, Apla and Confinterim and belonging to Confindustria, the Association of the Italian Firms). This solution reinforced the negotiation powers of the agencies. Moreover, the global economic crisis, one of the strong exogenous events of considerable importance, influenced the Government policies, the behaviours of the TWAs client companies, the workers and the agencies themselves.

Following we provide a table that summarize the events we have listed and described, according to the two dimension

Table 1. An overview of the main events in the TWAs field

Incubation phase (1986 - 1997)

Exogenous and background events

Events related

to the field

\begin{tabular}{|l|l|}
\hline EU Directive & $\begin{array}{l}\text { Social pact } \\
\text { Treu Law }\end{array}$ \\
\hline $\begin{array}{l}\text { Syntex takeover by Adia } \\
\text { "Mazzocca" Law Decree }\end{array}$ & $\begin{array}{l}\text { De Michelis Law } \\
\text { Foundaton of the "Club di Milano" } \\
\text { Founding of Assilt }\end{array}$ \\
\hline Weak events & Strong events
\end{tabular}


Emergence phase (1997 - 2003)

Exogenous and

background events

Events related

to the field

Development phase (2003 - 2009)

Exogenous and

background events

Events related

to the field

\begin{tabular}{|l|l|}
\hline Rise of the Berlusconi Government & White Paper \\
Debate on article 18 & Agreement of 2002 \\
Murder of Professor Biagi & Biagi Law \\
\hline Founding of Confinterim, AILT and APLA & $\begin{array}{l}\text { Founding of Ebitemp } \\
\text { and Forma.temp }\end{array}$ \\
\hline
\end{tabular}

Weak events

Strong events

\begin{tabular}{|l|l|}
\hline $\begin{array}{l}\text { Rise of the left-center Government } \\
\text { Rise of the } 2^{\text {nd }} \text { Berlusconi Government }\end{array}$ & Economic crisis \\
\hline $\begin{array}{l}\text { Founding of Ebiref } \\
\text { Legislative measures to reinforce TWAs' } \\
\text { role }\end{array}$ & $\begin{array}{l}\text { Ebitemp Activities } \\
\text { Founding of Assolavoro }\end{array}$ \\
\hline Weak events & Strong events \\
\hline
\end{tabular}

\subsection{Competing Logics in the TWAs Field}

Our study shows and describes the evolution of the TWAs field characterized by the coexistence of two competing logics that have affected the Italian labour market over the past twenty-five years.

Firstly, we investigate the role of actors involved in the emergence of the TWAs field and the events that have conditioned different logics that affected the field. By identifying the phases that have led to the emergence of the field, we can distinguish events that, on the one hand, spring directly from the actions undertaken by individual actors in the field or collective actors, and, on the other hand, exogenous events that shape the actors' actions and the rise of dominant logics.

In fact, the actions of the individual or collective actors activated many events by giving life to more or less explicit lobbying activities. Many individual actors belonging to the field (managers, consultants, business people, unionists, etc.) have directly or indirectly (through seminars, conferences, meetings with the minister and the government and discussions with the unionists) pursued a series of actions with the purpose of influencing the field regulations (causing decrees, law, ministerial memorandums, framework agreements and the National Collective Bargaining Agreement).

It is interesting to note, in this sense, the role of the media and press supporting the social legitimacy of the agency contract and thereby encouraging politicians to introduce measures to facilitate its development. Moreover an intense organization of seminars and conferences and the dissemination of studies and research consistently came out in different times.

The bilateral organizations Ebitemp and Forma.temp, and Assolavoro have played a crucial role during the three phases, replacing the government's welfare policies to care for agency workers who were considered not sufficiently protected by public welfare. For example, Ebitemp introduced some measures to support income and to facilitate access to credit.

In light of these considerations, a crucial focus concerns the relationship between the events occurring in the field and the institutional logics. We highlights the coexistence in the TWAs field of two competing logics: the regulation logic, inspired by the social status and welfare, and the de-regulation logic, connected to liberal and free-market models.

The regulation logic was formed in Italy following the struggles of workers and trade union movements that culminated with the approval of the Workers' Statute (1970). This logic refers to a series of laws and regulations designed to protect workers, the stability of the employment relationship and the role of the trade unions. The regulation logic focuses on protecting workers' rights, on the possibility of widening the scope of collective national contracts and the effort to limit management's employment activity. Moreover, this logic identify the permanent full-time contract as the unique type of employment for the Italian workers.

The de-regulation logic sprouted in Italy in the early 1990s when the need for companies to be flexible became somewhat stronger due to the gradual process of market globalization. This second institutional logic is based on a more liberal approach leading to a more flexible labour market with less strict barriers. Actors supporting the 
de-regulation logic strength and justify flexible forms of work within companies, rejecting job insecurity and precariousness provided by trade unions and leftist political parties. With the de-regulation logic, the emphasis shifted from the protection of a permanent job to the worker's employability.

As already mentioned, we emphasize three significant "breaking points": Treu Law, Biagi Law, and the socio-economic crisis. The Treu Law marks the field's emergence in an institutional context that is still heavily influenced by a regulation logic, although the event started to scale it down, leaving space for a new minor de-regulation logic. The second breaking point, the Biagi Law, represents the achievement of a coexistence between the two different logics, with the dominance of the de-regulation one until 2009. Finally, the crisis heavily changed the scenario, affecting the behaviours of the actors within the field. In fact, although the coexistence of the two logics remains, the crisis unbalanced the dominance, weakening the de-regulation logic, due to measures based on the protection of agency workers (Figure 1).

Therefore, from the analysis of the emergence of the field and the development process, we observe that the transition from one phase to another is marked by these breaking points that represent a radical change in the balance between the prevailing of the two institutional logics.

Until the 1980s, the dominance of the regulation logic characterizes the Italian labour market. After the Treu Law it continued to dominate since the decision to maintain the ban on brokerage, the obligation of exclusivity, the providing of an authorization process and the many constraints on the TWAs activity, represent features to maintain high barriers to the field.

Anyway after 1997, during the field's emergence phase (1997-2003), the regulation logic slightly started to weaken. In this period, many endogenous and exogenous events, endured or activated directly by actors of the field, animate the opposition of the logic. Such as the rise of the Berlusconi government in 2001, the 2002 union agreement, the publishing of the White Paper and, most of all, the founding of Ebitemp and Forma.temp and their following activities to support workers by replacing public welfare. The approval of the Biagi Law enshrined this weakening process.

The scenario starts to change in 2003. Despite the presence of a strong coercive pressure (the Biagi Law), TWAs, due to the higher competition among the field, start to implement organizational differentiation strategies. During the development phase (2003 - 2009), there is coexistence between the two institutional logics. Except for a short break in 2006 caused by the rise of the centre-left government, the main contents of the Biagi Law are not changed.

During the incubation and the development phases of the TWAs field, we notice how the regulation logic gradually left space for the de-regulation logic, leading to a coexistence of them and then in the development phase (2003-2009) to the dominance of the de-regulation logic.

During this period, there is a slow and continuous dissemination of the need for greater liberalization of the labour market but, at the same time, the main trade unions and some centre and leftist parties were working to struggle this emerging drive. Moreover, in these two phases, we examine the combination of two different models. The first one is inspired by a liberalist vision of the labour market that is flexible, attentive to the needs of businesses and interested in limiting the restrictions on the use of the agency contract. The second one, on the opposite, is inspired by the need to regulate the labour market and to protect agency workers, thus, inclined to maintain strict constraints on how TWAs use the contract and the criteria of firms to use the temporary agency employment.

The socio-economic crisis upset the balance. In fact, the "laissez faire" approach that have characterized the economic governance until then weaken and the measures adopted in the labour market are characterized by a strong use of public resources to protect workers and to reinforce the social status, mainly through income support instruments.

Following we provide a figure that shows how the two logics we describe have characterized the field during the three phases, competing each other and coexisting. 


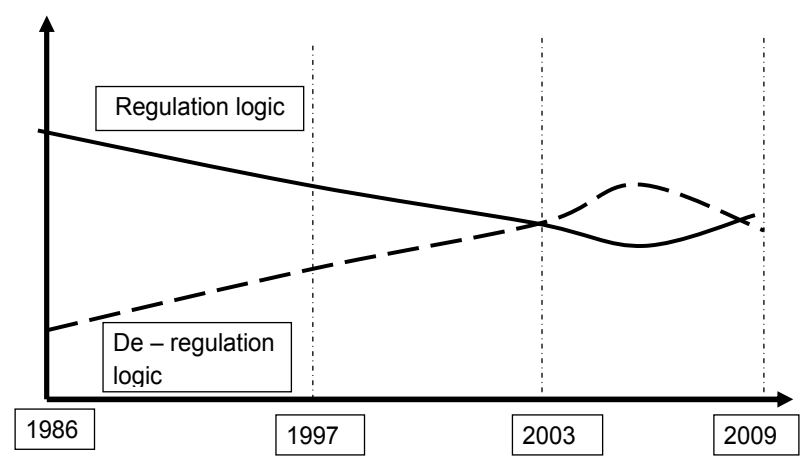

Figure 1. Competing logics in the TWAs field

\section{Conclusions and Suggestions for Future Researches}

In this paper, we have described the process of emergence and evolution of organizational field according to institutional logics approach. Thus, different institutional logics in different historical moments influence the emergence and evolution of the organizational field, and the behaviour of the actors that animate the field (e.g. Hoffman, 1999; Scott, Ruef, Mendel, \& Caronna, 2000; Seo \& Creed, 2002; Thornton 2004; Greenwood \& Suddaby, 2006; Thornton \& Ocasio, 2008). In particular, on the one hand, the institutional logics and, the institutional order that pervades, at a higher level, the different aspects of the Italian society (social and economic culture and politics) on the other hand, play a pivotal role by characterizing the economy and specifically the Italian labour market. In this context, some of the actions that occur during week or strong events help to explain stability or change of the field at a certain time. In particular, this work studies the institutional logics that constitute, on the one hand, the background of the individual and collective actions and, on the other hand, the effect of these actions.

Our work contributes to institutional theory at different levels. First, we can give some considerations on the sequence of strong and weak events and the relationship between actors, events and logics. In particular, we point out the ability of actors to generate some of the events that occur in the field and consequent shift from one logic to another. Secondly, we observe that the regulatory frame strongly influences the strategic and organizational behaviour of the actors within the Italian field of TWAs. Therefore, the actors face an institutional complexity to which they try to answer with a series of individual and collective actions aimed at influencing the same logics through a mutual conditioning that may be more or less direct.

Moreover, our work contributes to the institutional theory from the methodological point of view. The longitudinal analysis is able to explain phenomena hardly to describe with other methods. As a matter of fact through an in depth research repeated in four different field studies, our study manages to reconstruct the process of evolution of the TWAs field, describing the links between different phases.

As far as concerns our future researches, it would be very interesting to repeat a new field study (from 2009 to 2017) to analyze the role of the government into the economic system and the effect of the debate about the exit mechanism from Italian labour market (Art. 18). Moreover, it would be significant to study events, logics, role of actors and strategies adopted in this period, in order to identify new phases and to depict process of changes in the Italian field of TWAs and in the competing logics.

\section{References}

Consiglio, S., \& Moschera, L. (2016) (Eds.). Temporary Work Agencies in Italy. Evolution and Impact on the Labour Market. Springer, SpringerBriefs in Economics.

Consiglio, S., \& Moschera, L. (2010). Le agenzie per il lavoro e le risposte strategiche e organizzative alla crisi economica. Ebitemp, Franco Angeli, Milan.

Consiglio, S., \& Moschera, L. (2008). Dall'Interinale ai Servizi per il Lavoro. Franco Angeli, Milan.

Consiglio, S., \& Moschera, L. (2005). Le Agenzie per il Lavoro. Organizzazione, Regolazione, Competitività. Il Sole24Ore, Milan.

Consiglio, S., \& Moschera, L. (2001). Le Società di Fornitura di Lavoro Temporaneo in Italia. Organizzazione e Performance. Franco Angeli, Milan. 
Consiglio, S., \& Moschera, L. (2001). Le risposte organizzative alla regolazione istituzionale nella fase di nascita di un campo organizzativo: le Società Fornitrici di lavoro temporaneo in Italia. In Costa, G. (Eds.). Flessibilità \& Performance. L'organizzazione aziendale tra old e new economy, ISEDI, Turin.

Consiglio, S., \& Moschera, L. (2001). Flessibilità e Regolazione Istituzionale: le Agenzie di Lavoro Temporaneo in Italia. In Costa, G. (Eds.). Flessibilità and Performance. L'organizzazione Aziendale tra Old e New Economy (pp. 104-117). ISEDI, Turin.

Consiglio, S., \& Moschera, L. (2002). Il Lavoro Temporaneo in Italia. Sviluppo e Organizzazione, 189, 51-62.

Durand, R., \& Jourdan, J. (2012). Jules or Jim: Alternative Conformity to Minority Logics, Academy of Management Journal, 55(6), 1295-1315. https://doi.org/10.5465/amj.2011.0345

Friedland, R., \& Alford, R. R. (1991). Bringing Society Back: Symbols, Practices, and Institutional Contradictions. In Powell, W. W., \& DiMaggio, P. J. (Eds.). The New Institutionalism in Organizational Analysis. University of Chicago Press, Chicago.

Greenwood, R., Diaz, M. A., Li S. X., \& Cespedes Lorente, J. J. (2010). The multiplicity of Institutional Logics and the Heterogeneity of Organizational Responses. Organization Science, 21(2), 521-539. https://doi.org/10.1287/orsc.1090.0453

Greenwood, R., Oliver, C., Suddaby, R., \& Sahlin, K. (2008). Organizational Institutionalism. Sage, London.

Greenwood, R., Rayanard, M., Kodeih, F., Micelotta, E. R., \& Lounsbury, M. (2011). Institutional Complexity and Organizational Responses. The Academy of Management Annals, 5(1), 317-371. https://doi.org/10.1080/19416520.2011.590299

Greenwood, R., \& Suddaby, R. (2006). Institutional Entrepreneurship in Mature Field: the Big Five Accounting Firms. Academy of Management Journal, 49(1), 27-48. https://doi.org/10.5465/AMJ.2006.20785498

Greenwood, R., Suddaby, R., \& Hinings, C. R. (2002). Theorizing change: the role of professional associations in the transformation of institutionalized fields. Academy of Management Journal, 45(1), 58-80. https://doi.org/10.2307/3069285

Hensman, M. (2003). Social Movement Organizations: A Metaphor for Strategic Actors in Institutional Fields. Organization Studies, 24(3), 355-381. https://doi.org/10.1177/0170840603024003908

Hoffman, A. J. (1999). Institutional Evolution and Change: Environmentalism and the U.S. Chemical Industry. Academy of Management Journal, 42(4), 351-371. https://doi.org/10.2307/257008

Lounsbury, M. (2007). A Tale of Two Cities: Competing Logics and Practice Variation in the Professionalizing of Mutual Funds. Academy of Management Journal, 50(2), 289-307. https://doi.org/10.5465/AMJ.2007.24634436

Lounsbury, M., \& Crumley, E. T. (2007). New Practice Creation: An Institutional Perspective on Innovation. Organization Studies, 28(7), 993-1012. https://doi.org/10.1177/0170840607078111

Lounsbury, M. (2002). Institutional Transformation and Status Mobility: The Professionalization of the Field of Finance. Academy of Management Journal, 45(1), 255-267. https://doi.org/10.2307/3069295

Marquis, C., \& Lounsbury, M. (2007). Vive la Resistance: Competing Logics and the Consolidation of U.S. Community Banking. Academy of Management Journal, 50(4), 799-820. https://doi.org/10.5465/AMJ.2007.26279172

Meyer, A. D., Brooks, G. R., \& Goes, J. B. (1990). Environmental jolts and industry revolutions: Organizational responses to discontinuous change. Strategic Management Journal, (special issue), 93-110.

Meyer, J., \& Rowan, B. (1977). Institutionalized Organizations: Formal Structure as Myth and Ceremony. American Journal of Sociology, 83(2), 340-363. https://doi.org/10.1086/226550

Moschera, L., Consiglio, S., Berni, A., \& Cicellin, M. (2011). Logiche istituzionali e allomorfismo in un campo organizzativo: le Agenzie per il Lavoro in Italia. Studi Organizzativi, 2, 13-43.

Nicolini, D., Delmestri, G., Goodrick, B., Reay, T., Lindberg, K. \& Adolfsson, P., (2016). Look What's Back! Institutional Complexity, Reversibility and the Knotting of Logics. British Academy of Management, 27(2), 228-248. https://doi.org/10.1111/1467-8551.12156

Reay, T., \& Hinings, C. R. (2005). The Recomposition of an Organizational Field: Health Care in Alberta. Organization Studies, 26(3), 351-384. https://doi.org/10.1177/0170840605050872 
Reay, T., \& Hinings C. R. (2009). Managing the Rivalry of Competing Institutional Logics. Organization Studies, 30(6), 629-652. https://doi.org/10.1177/0170840609104803

Seo, M. G., \& Creed, W. E. D. (2002). Institutional Contradictions, Praxis and Institutional Change. A Dialectical Perspective. Academy of Management Review, 27(2), 222-247.

Scott, W. R., Ruef, M., Mendel, P., \& Caronna, C. (2000). Institutional Change and Health Care Organizations: From Professional Dominance to Managed Care. University of Chicago Press, Chicago.

Scott, W. R. (2008). Institutions and organizations: Ideas and interests. Sage, Thousand Oaks, CA.

Sewell, W. H. Jr. (1996). Historical Events as Transformations of Structures: Inventing Revolution at the Bastille. Theory and Society, 25(6), 841-881. https://doi.org/10.1007/BF00159818

Suddaby, R., \& Greenwood, R. (2005). Rhetorical Strategies of Legitimacy. Administrative Science Quarterly, 50(1), 35-67. https://doi.org/10.2189/asqu.2005.50.1.35

Thornton, P. H. (2002). The Rise of the Corporation in a Craft Industry: Conflict and Conformity in Institutional Logics. Academy of Management Journal, 45(1), 81-101. https://doi.org/10.2307/3069286

Thornton, P. H. (2004). Markets from Culture. Stanford Business Books, Stanford CA.

Thornton, P. H., \& Ocasio, W. (1999). Institutional Logics and the Historical Contingency of Power in Organizations: Executive Succession in the Higher Education Publishing Industry, 1958-1990. The American Journal of Sociology, 105(3), 801-843. https://doi.org/10.1086/210361

Thornton, P. H., \& Ocasio, W. (2008). Handbook of Organizational Institutionalism. Sage, London.

Thornton, P. H., Ocasio, W., \& Lounsbury M. (2011). The Institutional Logics Perspective. Oxford: Oxford University Press.

Westenholz, A. (2011). Hybridization as an organizational response to widespread institutional logics: A case of commercial and open source software community. ABC-Network Workshop, 30 September-1 October, Boston, MA.

\section{Notes}

Note 1. The Treu Law (Law 196/97) "Norme in materia di promozione dell'occupazione" takes its name from the former Italian Minister of Labour, Tiziano Treu, who was its chief promoter.

Note 2. The so-called Biagi Law (Law 30/2003) "Delega al Governo in materia di occupazione e mercato del lavoro" takes its name from chief promoter Marco Biagi.

Appendix A - Summary of the longitudinal analysis and field studies

\begin{tabular}{|c|c|c|c|c|}
\hline 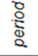 & $1986-1999$ & 2000-2004 & 2005-2006 & 2007-2009 \\
\hline 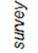 & 2000 & 2005 & 2007 & 2009 \\
\hline \multirow{6}{*}{ 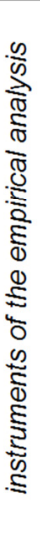 } & \multicolumn{4}{|c|}{ examination of information material } \\
\hline & \multicolumn{4}{|c|}{ studying of specialized press } \\
\hline & \begin{tabular}{|l}
40 interviews to experts, \\
trade unionists, actors \\
involved in lobbying. \\
trade association \\
execatives, managers and \\
owners of TWAs
\end{tabular} & $\begin{array}{l}33 \text { interviews to experts, } \\
\text { trade unicists, actors } \\
\text { involved in lobbying. } \\
\text { trade asscciation } \\
\text { executives, managers } \\
\text { and owners of TWAs }\end{array}$ & $\mid$\begin{tabular}{|l}
32 interviews to experts, \\
trade unionists, actors \\
involved in lobbying. \\
trade association \\
executives, managers \\
and owners of TWAs
\end{tabular} & \begin{tabular}{|l}
22 interviews to experts, \\
trade unionists, actors \\
involved in lobbying, \\
trade association \\
executives, managers and \\
owners of TWAs
\end{tabular} \\
\hline & $\begin{array}{l}30 \text { questionnaires dealing } \\
\text { with quantitative features } \\
\text { of TWAs and with } \\
\text { management's } \\
\text { perceptions }\end{array}$ & $\begin{array}{l}40 \text { questionnaires } \\
\text { dealing wth quantitative } \\
\text { features of TWAs and } \\
\text { with manggement's } \\
\text { perceptions }\end{array}$ & $\begin{array}{l}31 \text { questionnaires } \\
\text { dealing with quantitative } \\
\text { features of TWAs and } \\
\text { with management's } \\
\text { perceptions }\end{array}$ & $\begin{array}{l}36 \text { questionnaires dealing } \\
\text { with quantitative features } \\
\text { of TWAs and with } \\
\text { management's } \\
\text { perceptions }\end{array}$ \\
\hline & $\begin{array}{l}\text { analysis of reports and } \\
\text { financial statements } \\
\text { (1995-1999-2000) of } \\
\text { all TWAs }\end{array}$ & 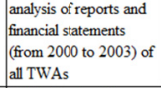 & $\begin{array}{l}\text { analysis of reports and } \\
\text { financial statements } \\
\text { (from 2004 to 2006) of } \\
\text { all TWAs }\end{array}$ & $\begin{array}{l}\text { analysis of reports and } \\
\text { financial statements (from } \\
2007 \text { to 2009) of all } \\
\text { TWAs }\end{array}$ \\
\hline & $\begin{array}{l}\text { TWAs involved the } \\
\text { surveying in terms of } \\
\text { turnover, represent } 80 \% \\
\text { of the market }\end{array}$ & $\begin{array}{l}\text { TWAs imolved the } \\
\text { surveying in terms of } \\
\text { turnover, represent 86\% } \\
\text { of the makket }\end{array}$ & $\begin{array}{l}\text { TWAs involved the } \\
\text { surveying in terns of } \\
\text { turnover, represent } 77 \% \\
\text { of the market }\end{array}$ & $\begin{array}{l}\text { TWAs involved the } \\
\text { surveying in terms of } \\
\text { turnover, represent } 75 \% \\
\text { of the market }\end{array}$ \\
\hline
\end{tabular}

\section{Copyrights}

Copyright for this article is retained by the author(s), with first publication rights granted to the journal.

This is an open-access article distributed under the terms and conditions of the Creative Commons Attribution license (http://creativecommons.org/licenses/by/4.0/). 